\title{
Home-built Solid-state NMR Probe for Membrane Protein Studies
}

\author{
Yongae Kim," Jung-Hyun Hwang, and Jae-Joon Park \\ Dept of Chemistr, Mankuk University of Foreign Studies, San 89, Mohyun, Yongin 4+49-791, Korea \\ Received Mov 26, 2003
}

\begin{abstract}
Proteins in highly oriented lipid bilayer samples are useful to study membrane protein structure determination. Planar lipid bilayers aligned and supported on glass slide were prepared. These stack of glass slide with planar lipid bilayers are not well fit for commercial solid-state NMR probe with round coil. Therefore, homebuilt solid-state NMR probe was built and used for a stack of thin glass plates and RF coil is wrapping directly around the flat square sample. The overall filling factor of the coil is nuch better and the large surface area enhances the extent to orientation by providing uniform environments for the phospholipids and the high ratio of circumterence to area reduces edge effects. ${ }^{1} \mathrm{H}$ and ${ }^{15} \mathrm{~N}$ double resonance probe for $400 \mathrm{MHz}$ NMR (9.4T) with a flat coil (coil size: $11 \mathrm{~mm} \times 20 \mathrm{~mm} \times 4 \mathrm{~mm}$ ) is constructed and tested.
\end{abstract}

Key Words : Home-built solid-state NMR probe, Membranc proteins

\section{Introduction}

Approximately $30 \%$ of all expressed polypeptides are membrane-associated but neither X-ray crystallography nor solution nuclear magnetic resonance (NMR) spectroscopy is very effective for these proteins. The lipids required for the structural integrity and functionality of membrane proteins impede crystallization as well as the rate of overall reorientation in solution. Solid-state NMR experiments on lipid bilayer samples are especially valuable for membrane proteins with predominantly helical secondary structure. High resolution solid-state NMR spectroscopy is capable of determining the backbone and side chain structures of membrane proteins. Solid-state NMR spectra of imınobile molecules have very broad resonance signals because the anisotropic spin interactions are not averaged out by molecular motions. Irradiation of RF pulse and/or sample manipulations can lead to the selective averaging and separation of the spectral manifestations of the anisotropic spin interactions. The spin interactions can be probed through radio frequency ( $\mathrm{rf}$ ) irradiations and sample manipulations that lead molecular reorientation as a line-narrowing mechanisın. Solid-state NMR of oriented samples takes advantages of the spectral simplifications that result from uniaxial orientation parallel to the direction of the applied magnetic field. The spin interactions at ${ }^{15} \mathrm{~N}-,{ }^{1.7} \mathrm{C}$, and ${ }^{2} \mathrm{H}$ labeled sites yield signals that can be characterized by single resonance frequencies in each of several dimensions. ${ }^{1-6}$ The observed frequencies depend on the orientations of the principal axes of the spin-interaction tensors, present at each site, relative to the direction of the applied magnetic field.

A commonly used technique for aligning membrane bilayers involves the deposition of a mixture of proteins and lipids onto glass plates followed by application of pressure, shear, centrifugal forces. ${ }^{7 \cdot 9}$ In this Study, about 30 rectangular glass plates are stacked in parallel so that the bilayer normal is parallel to the field of the magnet. Planar lipid bilayers aligned and supported on glass slide are prepared for uniaxial orientation.

\section{Experimental Methods}

Circuit Diagram for a Home-built ${ }^{1} \mathrm{H}^{15} \mathrm{~N}$ Double resonance Probe. Figure l shows a picture of a flat-coil probe designed for ${ }^{1} \mathrm{H}^{15} \mathrm{~N}$ double resonance experiments. Figure $1(a)$ is a whole probe body and Figure $l(b-d)$ are different view of the flat square coil (dimension is $11 \mathrm{~mm} \times$ $20 \mathrm{~mm} \times 4 \mathrm{~mm}$ ) with a sample in a polyethylene bag to keep the humidity. Figure 2 shows the general circuit diagram for a flat square coil probe. Capacitor $\mathrm{Cl}, \mathrm{C} 2$, and $\mathrm{C} 6$ are selected in conjunction with the $\lambda / 4$ line to tune and match the high frequency channel. The length of $\lambda / 4$ line can be calculated by using an equation ( 1 ). (a)

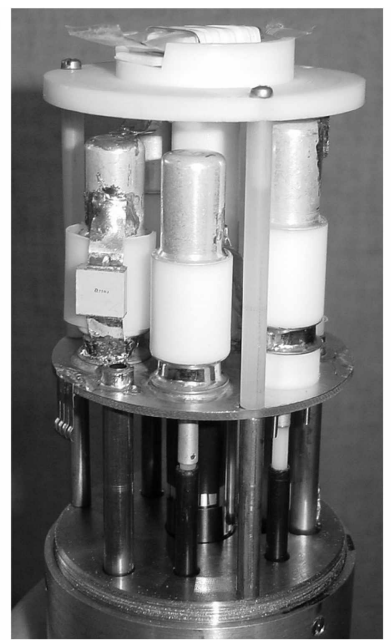

(b)

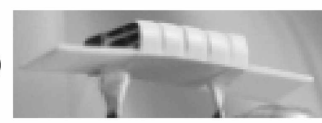

(c)

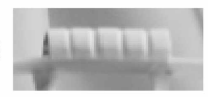

(d)

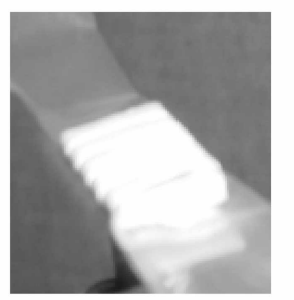

Figure 1. 'l'he pictures of the $400 \mathrm{MH} \%(9.41)$ home-built solidstale VMR probe with a llal square coil designed for 'HI and ${ }^{15} \mathrm{~V}$ double resonance experiments. (a) Whole probe (b-d) different viet of the flat square coil (dimension is $11 \mathrm{~mm} \times 20 \mathrm{~mm} \times 4 \mathrm{~mm}$ ) with a sample in a polyethylene bag to keep the humidity: 


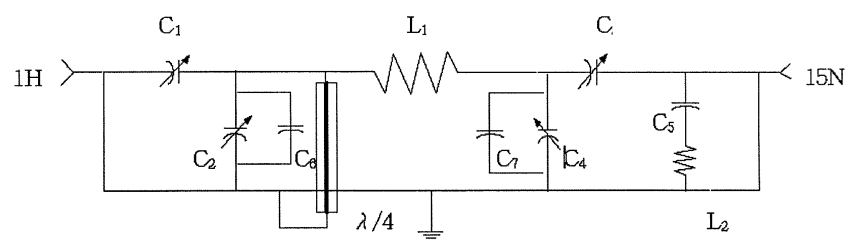

Figure 2. Circuit diagram for the ${ }^{1} \mathrm{H}$ and ${ }^{17} \mathrm{~N}$ double resonance probe with a llat square coil. $\mathrm{Cl}$ and $\mathrm{C2}$ are tuning and matching capacitor for 111 side that are $1.0-10 \mathrm{pt}$ variable capacitance (Poly flon). $\mathrm{C} 3$ and $\mathrm{C} 4$ are tuning and matching capacitor for ${ }^{15} \mathrm{~N}$ side that are 1.0-10pF variable capacitance (Polyflon). C5. C.6. and (C7 are fixed capacitors (AIC), I. 1 is al llat square copper coil of 5 turns thich dimension is $11 \mathrm{~mm} \times 20 \mathrm{~mm} \times 4 \mathrm{~mm}$. $\lambda_{i} 4$ is a cuarter lamda line which length is $12.5 \mathrm{~cm}$.

$$
\begin{aligned}
\lambda / 4 & -\mathrm{c} / 4 \\
& -\frac{3 \times 10^{16}(\mathrm{~cm} / \mathrm{sec}) \times 0.667 *}{4 \times 400 \times 10^{6}(\mathrm{sec})} \\
& -12.5(\mathrm{~cm})
\end{aligned}
$$

(*: Inside the dielectric of the coaxial cable is 0.667 )

Then $\mathrm{LI}$ flat square coil is added to the circuit and tuned. Capacitor $\mathrm{C} 3, \mathrm{C} 4$, and $\mathrm{C} 7$ are added to tune and match the low frequency channel. High frequency trap of $\mathrm{C} 5$ and $\mathrm{L} 2$ are used to tune the decoupled channel and provide the higher isolation between the decoupled frequency channel and observed channel. Tuning and matching of each frequency channel and isolation between two channels were measured by network analyzer (HP 8712ES).

Oriented lipid bilayer samples. To make an oriented lipid bilayer samples, codissolved vpu which are 81 residue accessory protein of human immunodeficiency virus type-1 (HIV-I) protein and phospholipids (DMPC and DMPG) are deposited from organic solvents followed by evaporation and lipid hydration with the glass surface. The stacked glass slide sample is wrapped in a thin layer of parafilm, and then placed in a thin film of polyethylene that is heat sealed at both ends to maintain sample hydration during the experiments. Figure ID shows an oriented protein in oriented bilayer sample in a sealed polyethylene bag.

Solid-state NMR Experiments. Solid-state NMR spectrum was obtained on a Chemagnetics-Otsuka Electronics (Ft. Collins, $\mathrm{CO}$ ) spectrometer with a wide bore Oxford $400 / 89$ magnet, using a home-built flat square coil probe double tuned to the resonance frequencies of $\mathrm{IH}$ at $400.3 \mathrm{MHz}$, and $15 \mathrm{~N}$ at $40.5 \mathrm{MHz}$. 1 dimensional $15 \mathrm{~N}$ chemical shift spectra were obtained with I ms contact time. CPMOIST (CrossPolarization with Mismatch Optimized IS Transfer) crosspolarization to generate $15 \mathrm{~N}$ magnetization. The 2D PISEMA experiment was using flip-flop, phase- and frequency switched Lee-Goldburg homonuclear decoupling to provide line-narrowing in the $1 \mathrm{H}-15 \mathrm{~N}$ dipolar coupling dimension.

\section{Results and Discussion}

Specifications of the home-built square flat coil probe are summerized at Table 1. Quality factor of home-built probe
Table 1. Specilication of the home-built flat square coil probe of 'II and ${ }^{15} \mathrm{~N}$ double resonance for $400 \mathrm{MHz}$

\begin{tabular}{ll}
\hline Coil Jimension & $11 \times 20 \times 4 \mathrm{~mm}$ (5 lumss) \\
\hline Inductance & $49 \Omega$ \\
Quality factor & $1 \mathrm{H}: 220 \quad: 15 \mathrm{~N}: 105$ \\
lsolation & High $\rightarrow$ Low: $29 \mathrm{~dB}:$ Low $\rightarrow$ High: $29.6 \mathrm{~dB}$ \\
Power Capability: & $1 \mathrm{H} \mathrm{Dec:}: 2.3 \mu \mathrm{s} 90^{\prime \prime}: 15 \mathrm{~N} 90^{\circ}: 4.5 \mu \mathrm{s}$ \\
\hline
\end{tabular}

(a)
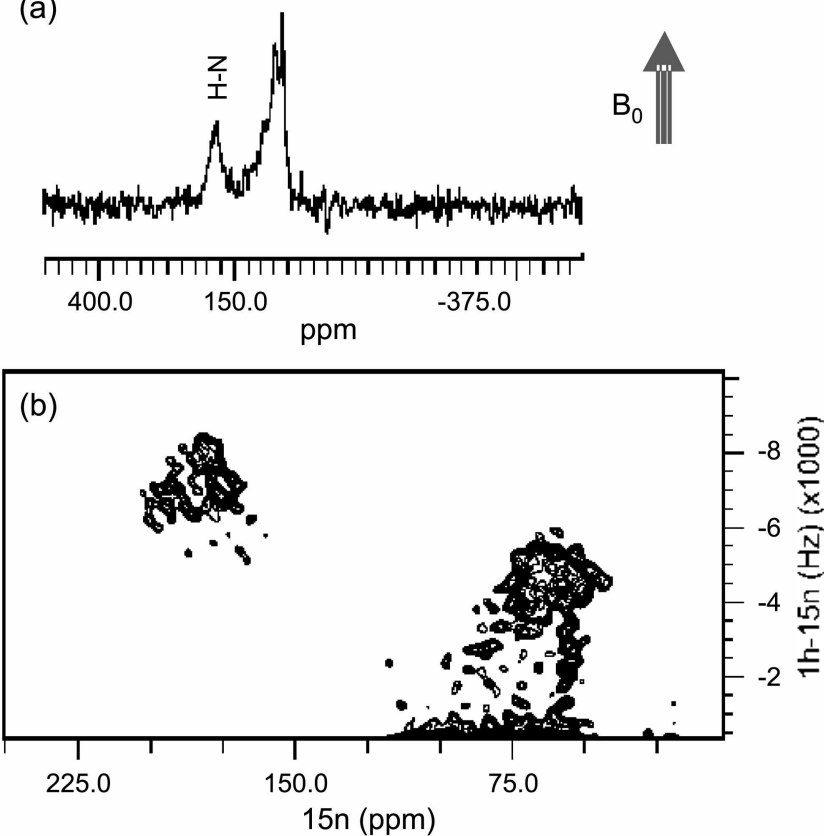

Figure 3. ID and 2D solid-state VMR spectra of uniformly " $\mathrm{V}$ labeled vpu in oriented bilayers. (a) ${ }^{15} \mathrm{~N}$ ehemical shilt solid-state NMR spectrum of vpu in lipid bilayers oriented on glass slides. Residues in the transmembrane helix have $\mathrm{N}-\mathrm{H}$ bonds oriented approximately parallel to the lield and residues in the protein amphipathic in -plane helix have their V-II bonds perpendicular to the field. (b) The ${ }^{15} \lambda$ ehemieal shift and ${ }^{1} \mathrm{H}-{ }^{15} \mathrm{~N}$ d dipolar coupling trequencies measured from the two-dimensional PISE.MA spectrum. This 2D solid state VMR spectrum provided the orientalional constraints for strucure determination of $15 \wedge$ labeled vpu in lipid bilayer membranes.

and isolation between high frequency channel and low frequency channel is high enough to measure high resolution solid-state NMR spectrum. RF power durability of the home-built solid state NMR probe is high enough for more than I $\mathrm{kW}$. Especially for ${ }^{1} \mathrm{H}$ and ${ }^{15} \mathrm{~N}$ cross polarization experiments like PISEMA (Polarization Inversion with Spin Exchange at the Magic Angle $)^{10-16}$ require more than $\mathrm{IkW}$ for low frequency channel. Figure 3 shows ID and 2D solidstate NMR spectra of vpu which are 81 residue accessory protein of human immunodeficiency virus type-I (HIV-I) in oriented phospholipids bilayers obtained with home-built solid-state NMR probe. More than IkW RF power was required for ${ }^{15} \mathrm{~N}$ frequency channel but there is no probe arcing detected. The ${ }^{15} \mathrm{~N}$ chemical shift depends on the helix orientation are obtained from 1D spectrum. The ${ }^{15} \mathrm{~N}$ chemical shift and ${ }^{1} \mathrm{H}-{ }^{15} \mathrm{~N}$ dipolar coupling frequencies were 
measured from the two-dimensional PISEMA spectrum. This 2D solid state NMR spectrum provided the orientational constraints for structure determination of ${ }^{15} \mathrm{~N}$ labeled vpu in lipid bilayer membranes. Detailed stnıctural infomation will be discussed in other paper.

\section{Conclusions}

Home-built solid state NMR probe of ${ }^{1} \mathrm{H}$ and ${ }^{15} \mathrm{~N}$ double resonance with square flat coil for $400 \mathrm{MHz}$ was successfully made and tested. All specification including probe quality factor isolation between high frequency channel and low frequency channel. and RF power durability over $1 \mathrm{~kW}$ are satisfactory as Table I. ID and 2D solid-state NMR spectra of vpu in oriented bilayers with home-built solid state nmr probe were obtained without any arcing problems.

Acknowledgements. This work was supported by grant No. (R01-2001-00049) from the Korea Science \& Engineering Foundation. and HanKuk University of Foreign Studies Research Fund of 2003. This research utilized the resource for Solid-state NMR of Proteins supported by grant P4lRR09731 from the Biomedical Research Technology Program. National Center for Research Resources. National Institutes of Health.

\section{References}

1. Shon. K.: Kim. Y.: Colango, L. A.: Opella, S. J. Science 1991. 252. 1303 .

2. Shon. K.: Schrader. P.: Kim. Y: Bechinger. B.: Zasloff. M.: Opella. S. J. Biotechologn: Bridging Research and Applications 1991. 109

3. MeDonnel. P. A.: Shon, K.: Kim. Y: Opella. S. J. J. Mol Biol. 1993. $233,474$.

4. Opella. S. J: Kim. Y.: McDonnell. P. Methods in Enzymology 1994. 239.536.

5. Kim. Y. Biochemistry Nen's 2001. 21. 253 .

6. Jost. P. C.: Griftith. O. H. Arch. Biochent. Biophns. 1973. 159. 70.

7. Tanaka, H. Freed, J. H. J. Phus. Chem 1984, 88.6633.

8. Zhang. Q. W. at al. J. Magi. Res. 1998.132, 167.

9. Ramamoorthy. A.: Wu. C. H.: Opella. S. T. J. Am. Chem. Soc 1997. 119. 10479

10. Kim. Y: Valentine. K.: Opella. S. T.: Schendel. S. L.: Cramer. W. A. Protein Sci, 1998, 7, 343.

11. Opella. S. J.: Kim. Y; Valentine. K. G.; Marassi. F. M.: Zasiloff. M: Montal, M: Cramer W. A. J. Kor: Magi. Res. Soc. 1998. 2. 120

12. Marassi. F. M.: Gesell. T. J.: Valente. A. P.: Kim. Y:: Montal. M.: Opella. S. T. J. Bio M MR 1999. 1 t. 141.

13. Opella. S. J.: Marassi, F. M.: Gesell, J. J.; Valente, A. P; Kim, Y: Montal. M. Natwe Structwal Biology 1999, 6. 374.

14. Ramamoorthy, A.: Wu. C. H.; Opella. S. J. J. Hagn. Reson. 1999. 140. 131 .

15. Marassi. F. M.: Opella. S. J. J. Magn. Reson. 2000. HH. 150. 